Article

\title{
Effect of Thermal Treatment of Birch Wood by Saturated Water Vapor on Granulometric Composition of Chips from Sawing and Milling Processes from the Point of View of Its Processing to Composites
}

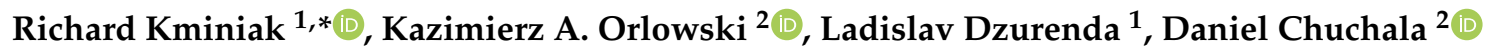 \\ and Adrián Banski ${ }^{1}$ \\ 1 Faculty of Wood Sciences and Technology, Technical University in Zvolen, 96053 Zvolen, Slovakia; \\ dzurenda@tuzvo.sk (L.D.); banski@tuzvo.sk (A.B.) \\ 2 Department of Manufacturing and Production Engineering, Faculty of Mechanical Engineering, \\ Gdansk University of Technology, Narutowicza 11/12, 80-233 Gdansk, Poland; korlowsk@pg.edu.pl (K.A.O.); \\ danchuch@pg.edu.pl (D.C.) \\ * Correspondence: richard.kminiak@tuzvo.sk; Tel.: +421-0904-827-285
}

Received: 1 October 2020; Accepted: 23 October 2020; Published: 27 October 2020

check for updates

\begin{abstract}
The goal of this work is to investigate the impact of thermal modification of birch wood with saturated steam on the particle size distribution of the sawing and milling process. Birch wood (Betula pendula Roth) is an excellent source to produce plywood boards. Wastes from mechanical processing of birch wood are suitable to produce composite materials. Granulometric analyses of chips from sawing processes on the PRW 15M frame saw, as well as on the 5-axis CNC machining centre SCM TECH Z5 and the 5-axis CNC machining centre AX320 Pinnacle, proved that more than $95 \%$ of chips are chips of coarse and medium coarse chip fractions with dimensions above $0.125 \mathrm{~mm}$. Depending on the shape, coarse and medium-thick chips belong to the group of fiber chips, the length of which is several times greater than the width and thickness. Fine fractions with dimensions smaller than $125 \mu \mathrm{m}$ are isometric chips that are approximately the same size in all three dimensions. Thoracic dust fractions below $30 \mu \mathrm{m}$ were not measured. The performed analyses showed that the heat treatment of birch wood with saturated steam did not affect the grain size of chips formed in sawing and milling processes on CNC machining centre and can be used as a raw material for the production of composite materials. Fabric filters are suitable for separating chips extracted from frame saws, PRW-15M or machining centre. Environmental criteria for the separation of chips from transport air in textile filters are met by filters with a fabric classified in class G4.
\end{abstract}

Keywords: birch wood; chips; wood composites; granulometric composition of sawdust and chips; air handling; ecological filtration

\section{Introduction}

Thermal treatment of wood with saturated water vapor, in addition to the targeted physico-mechanical changes of wood, is often used in the production of veneer and plywood, bent furniture, or pressed wood. The mentioned treatment is also frequently accompanied by chemical reactions causes the colour changing of wood [1-7]. While in the past, the colour changes of the darkening of thermally treated wood were used to eliminate undesirable colour differences between light beige and dark kernel, or to remove unwanted colour spots caused by evaporation, browning or molding, in recent times the research focuses on targeted changes in wood colour to more 
or less pronounced colour shades, namely wood imitations of domestic trees as exotic trees [8-12]. The influence of the hydro-thermal modification process on wood machinability was also investigated by Sandak et al. [13] with four minor species such as black poplar (Populus nigra L.), deodar cedar (Cedrus deodara Roxb.), black pine (Pinus nigra Arnold.) and alder (Alnus cordata Loisel) the sharpness of the tool has a lower importance for the final surface smoothness.

Chips from sawing and milling processes were characterized in the literature as a polydisperse bulk material consisting of coarse and medium coarse fractions with a grain size of $0.5-3.5 \mathrm{~mm}$, while the proportion of fine (dusty) fractions with smaller particle sizes below $300 \mu \mathrm{m}$ is not excluded [14-30]. Dzurenda and Orlowski [31] examined sawdust of thermally modified ash wood obtained during sawing on a sash gang saw PRW-15M, and they revealed increasing of chip homogeneity in the range of granularity $a=250 \mu \mathrm{m}-2.4 \mathrm{~mm}$. A combination of wood chips and pine sawdust (Pinus Sylvestris L.) with a percentage of sawdust of up to $50 \%$ positively affects the board quality by making its structure more homogeneous [32].

The geometry of wood elements used in composites production is one of the important factors affecting board properties. Therefore, the research of birch wood after its thermal treatment on granulometric composition of wood particles from sawing and milling processes is substantial when we consider how large volumes of birch wood are processed in the sawmill industry and in the formatting of plywood boards around the world (Youngquist [32], Maloney [33], and Istek et al. [34]). According to these studies, bending and modulus of elasticity as well as dimensional stability of composites improve with appropriate elements length used for composite production.

The aim of this work was to determine the effect of thermal treatment-modification of the colour of birch wood (Betula pendula Roth) by saturated water vapor upon grain size from cutting processes of thermally modified birch wood on different machine tools as follows: the sash gang saw PRW-15M, the 5-axis CNC machining centre SCM TECH Z5 and AX320 Pinnacle. Furthermore, specification of separation technique requirements for the mentioned processes have to be defined.

\section{Materials and Methods}

\subsection{Material}

Birch wood (Betula pendula Roth) in the form of tangential boards with dimensions: 40 (radial direction) $\times 80$ (tangential direction) $\times 600 \mathrm{~mm}$ (longitudinal direction), in total 180 samples, were divided into 3 groups consisting of 60 samples each. The initial moisture content MC of wet birch was in the range MC $=54.7-58.2 \%$. The samples in the Group 1 were not heat treated. The boards of the second group were heat treated with the MODE I and the blanks of third group were heat treated with the MODE II. Thermal treatment of birch wood with saturated water vapor was carried out in a pressure autoclave APDZ 240 (Himmasch AD, Haskovo, Bulgaria) installed at Sundermann Ltd. in Banska Stiavnica (Slovakia).

\subsection{Thermal Treatment}

The process of thermal treatment of birch timber with saturated water vapor (steam) is shown in Figure 1, and the technical parameters of each mode are given in Table 1. 


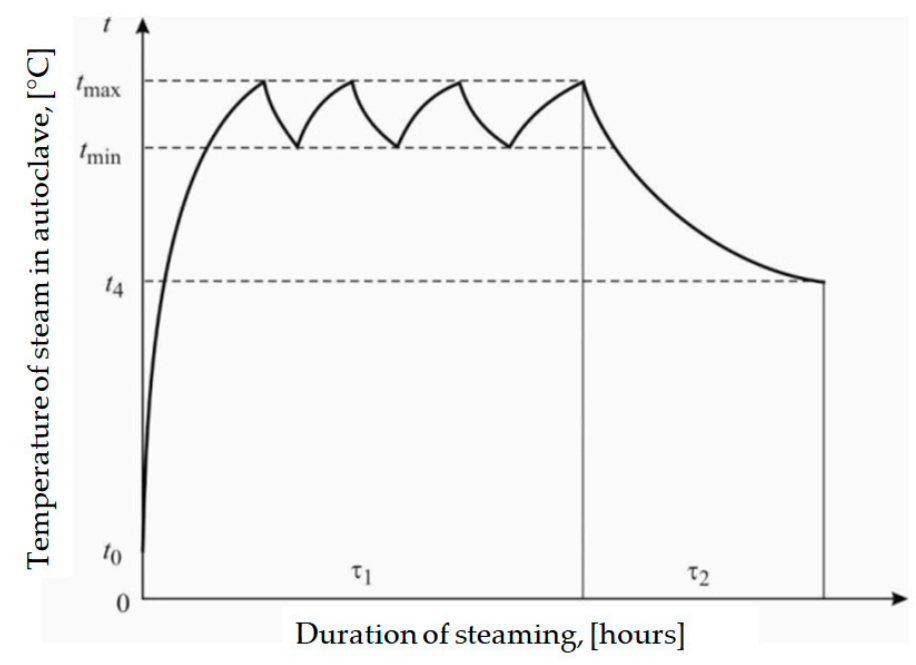

Figure 1. Mode of colour modification of birch wood with saturated water steam.

Table 1. Regimes for thermal treatment of the birch wood using saturated water vapor.

\begin{tabular}{ccccccc}
\hline Thermal & \multicolumn{2}{c}{ Temperature of Steam in Autoclave, $\left[{ }^{\circ} \mathrm{C}\right]$} & \multicolumn{3}{c}{ Duration of Steaming $\boldsymbol{\tau},[\mathrm{h}]$} \\
\cline { 2 - 7 } Treatment & $\boldsymbol{t}_{\text {max }}$ & $\boldsymbol{t}_{\mathbf{4}}$ & $\boldsymbol{\tau}_{\mathbf{1}}$ - stage I. & $\boldsymbol{\tau}_{\mathbf{2}}$-stage II. & Total $\boldsymbol{\tau}_{\mathbf{1}}+\boldsymbol{\tau}_{\mathbf{2}}$ \\
\cline { 2 - 7 } Regimes & $\boldsymbol{t}_{\text {min }}$ & 122.5 & 100 & 6.0 & 1.5 & 5.5 \\
\hline MODE I & 122.5 & 100 & 6.0 & 1.5 & 7.5 \\
MODE II & 132.5 & 137.5 & 10.5 \\
\hline
\end{tabular}

The temperatures $t_{\max }$ and $t_{\min }$ in Figure 1 are the intervals between which saturated water vapor is fed into the autoclave to carry out the technological process. Temperature $t_{4}$ is a parameter of the saturated water vapor pressure in the autoclave to which the autoclave vapor pressure must be reduced before the pressure equipment is safely opened.

Subsequently, thermally treated and not-thermally treated blanks were dried by a low-temperature regime without changing the colour of the wood to a moisture content $\mathrm{MC}=12 \pm 0.5 \%$ in a conventional hot-air dryer: KC 1/50 (SUSAR s.r.o). After the blanks were dried, a portion of the blanks from each group was used to produce $S T=5 \mathrm{~mm}$ thick slats on a PRW-15M, a portion of the blanks was machined on the 5 axis machining centre AX320 Pinnacle and a part of the blanks was milled on a machining centre SCM Tech Z5.

\subsection{Characteristics of Machine Tools and Milling Cutters}

\subsubsection{Narrow-Kerf Frame Sawing Machine (Sash Gang Saw) PRW-15M}

The lamellae were made from birch thermally untreated and treated wood on the frame sawing machine PRW-15M with the hybrid dynamically balanced drive system and elliptical tooth trajectory movement [35] at the Department of Manufacturing and Production Engineering (Gdańsk University of Technology, PL).

The sawing process for both type of materials was carried out with average cutting speed $v_{c}=3.69 \mathrm{~m} \cdot \mathrm{s}^{-1}$ and feed per tooth $f_{\mathrm{z}}=0.14 \mathrm{~mm}$. In the case of the frame sawing process, can be assumed that the value of feed per tooth is equal to the value of average uncut chip thickness, $f_{\mathrm{z}}=h_{\mathrm{av}}$ $=0.14 \mathrm{~mm}$ (Figure 2). The saw blades were sharp, with Stellite tipped teeth. The other basic parameters of frame saw and saw blades are shown in Table 2. 


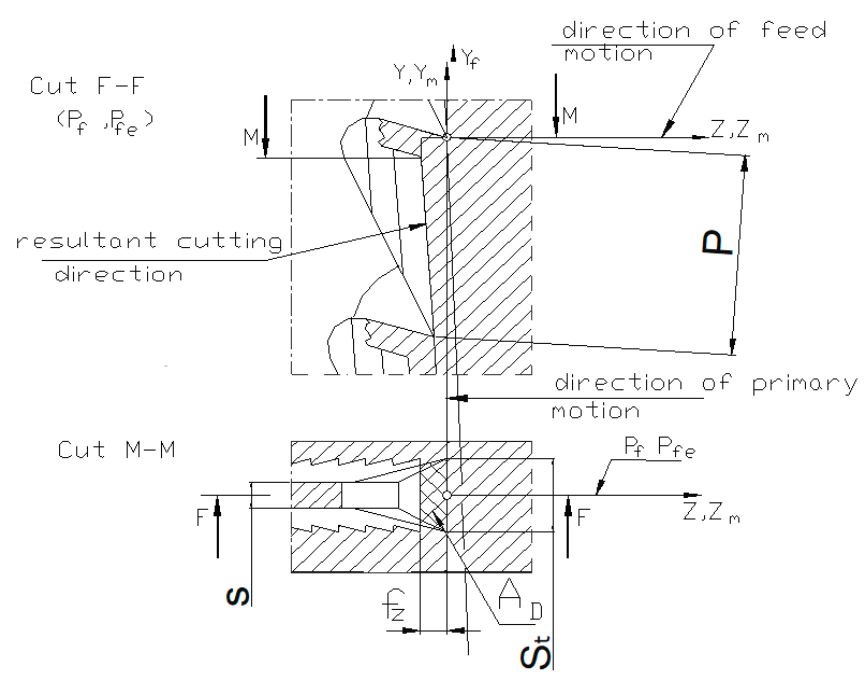

Figure 2. Mode sawing kinematics on the sash gang saw: fz-feed per tooth, s-saw blade thickness, AD-area of the cut, P-pitch, Y, Z and YM, ZM-machine coordinate and setting axes, Yf-f-set coordinate axis, Pfe-working plane.

Table 2. Machine tool and tool settings for frame sawing process.

\begin{tabular}{|c|c|c|c|}
\hline \multicolumn{4}{|c|}{ Machine Tool Settings } \\
\hline Name of Parameter & Symbol & Value & Unit \\
\hline Cutting speed & $v_{\mathrm{c}}$ & 3.69 & $\mathrm{~m} \cdot \mathrm{s}^{-1}$ \\
\hline Number of strokes of saw frame per min & $n_{\mathrm{F}}$ & 685 & spm \\
\hline Saw frame stroke & $H_{\mathrm{F}}$ & 162 & $\mathrm{~mm}$ \\
\hline Number of saws in the gang & $n$ & 5 & pcs \\
\hline Feed speed & $v_{\mathrm{f}}$ & 1183 & $\mathrm{~mm} \cdot \mathrm{min}^{-1}$ \\
\hline Feed per tooth & $f_{\mathrm{Z}}$ & 0.14 & $\mathrm{~mm}$ \\
\hline Uncut chip thickness & $h_{\mathrm{av}}$ & 0.14 & $\mathrm{~mm}$ \\
\hline \multicolumn{4}{|c|}{ Tool Settings } \\
\hline Name of Parameter & Symbol & Value & Unit \\
\hline Overall set (kerf width) & $S_{\mathrm{t}}$ & 2 & $\mathrm{~mm}$ \\
\hline Saw blade thickness & $s$ & 0.9 & $\mathrm{~mm}$ \\
\hline Free length of the saw blade & $L_{0}$ & 318 & $\mathrm{~mm}$ \\
\hline Blade width & $b$ & 30 & $\mathrm{~mm}$ \\
\hline Tooth pitch & $P$ & 13 & $\mathrm{~mm}$ \\
\hline Tool side rake angle & $\gamma_{\mathrm{f}}$ & 9 & $\circ$ \\
\hline Tool side clearance angle & $\alpha_{\mathrm{f}}$ & 14 & $\circ$ \\
\hline Tension stresses of saws in the gang & $\sigma_{\mathrm{N}}$ & 300 & $\mathrm{MPa}$ \\
\hline
\end{tabular}

\subsubsection{Milling Centre AX320 Pinnacle}

After the sawing process on the frame machine, the bigger parts of sawed samples were subjected to a milling process on 5 axis milling centre AX320 Pinnacle also located in GUT laboratory. The main parameters of milling process such as cutting speed $v_{\mathrm{c}}=3.69 \mathrm{~m} \cdot \mathrm{s}^{-1}$ (rotational speed $n=4405 \mathrm{~min}^{-1}$ ) and average uncut chip thickness $h_{\mathrm{avg}}=0.14 \mathrm{~mm}$ (feed speed $v_{\mathrm{f}}=2848 \mathrm{~mm} \cdot \mathrm{min}^{-1}$ ) were used the same values as for frame sawing process. The end milling cutter with blades from cemented carbide was used during experimental cutting tests. This cutter was manufactured by ASPI company, Suwalki, Poland and the main geometry dimensions of milling cutter (Figure 3) and main parameters of the milling process are shown in Table 3. The work movements of the tool were performed by the machine tool in accordance with the CNC program on the Heidenhain TNC 640 control system. The standard 
vice with jaws length $100 \mathrm{~mm}$ was used to fixture of samples (Figure 4). The height of the milling samples $H=25 \mathrm{~mm}$ was cut depth $a_{\mathrm{p}}$ also (Figure 4).
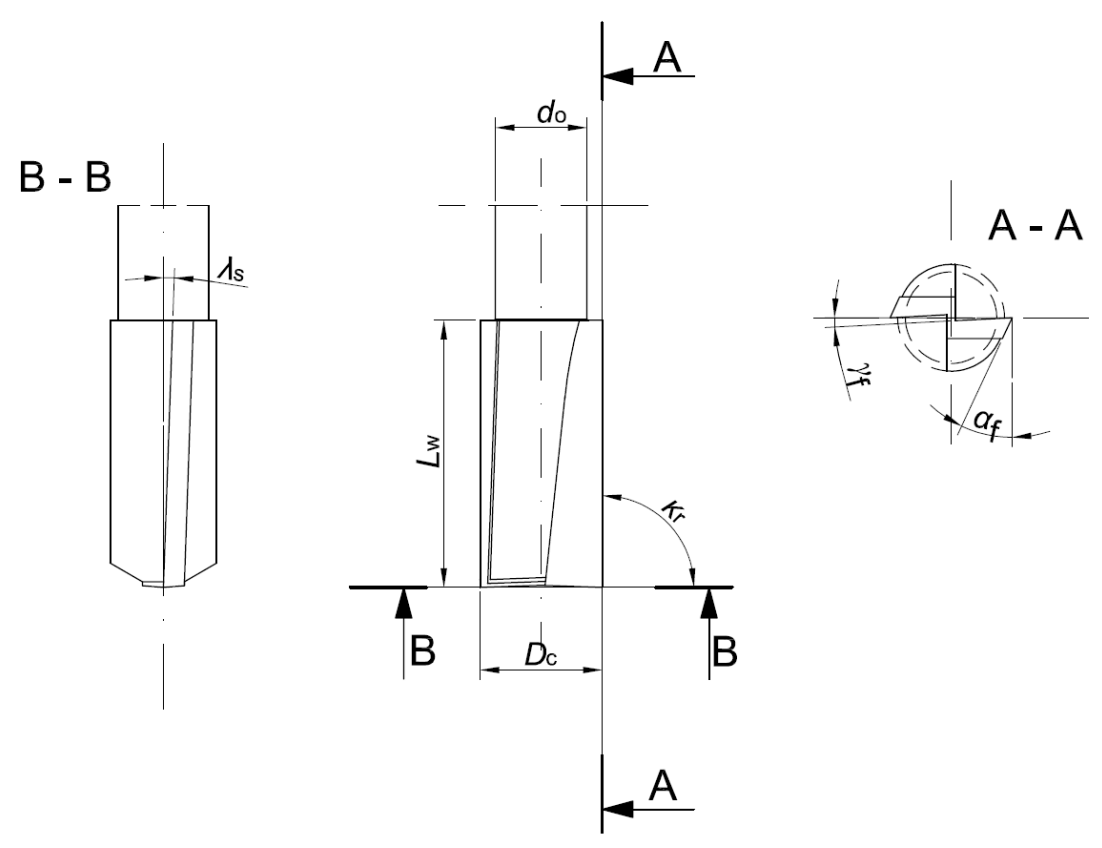

Figure 3. Cutting edge geometry of mill cutter used for wood milling process at the AX320 milling centre.

Table 3. Main parameters of milling cutters and milling processes.

\begin{tabular}{|c|c|c|c|c|}
\hline \multicolumn{5}{|c|}{ Milling Cutters Settings } \\
\hline \multirow{2}{*}{ Name of Parameter } & \multirow{2}{*}{ Symbol } & \multirow{2}{*}{ Unit } & \multicolumn{2}{|c|}{ Value } \\
\hline & & & AX 320 & SCM Tech Z5 \\
\hline Tool diameter [mm], & $D_{\mathrm{c}}$ & $\mathrm{mm}$ & 16 & 14 \\
\hline Shank diameter [mm], & $d_{\mathrm{o}}$ & $\mathrm{mm}$ & 12 & 14 \\
\hline Number of teeth $[-], z$ & $\mathrm{z}$ & - & 2 & 3 \\
\hline Tool length [mm], & $L_{\mathrm{t}}$ & $\mathrm{mm}$ & 70 & 110 \\
\hline Working length of the tool & $L_{\mathrm{C}}$ & $\mathrm{mm}$ & 35 & 58 \\
\hline Side rake angle & $\gamma_{\mathrm{f}}$ & $\circ$ & 3 & 35 \\
\hline Side clearance angle & $\alpha_{\mathrm{f}}$ & $\circ$ & 25 & 15 \\
\hline Tool cutting edge angle & $\kappa_{\mathrm{r}}$ & $\circ$ & 90 & 90 \\
\hline Cutting edge inclination angle & $\lambda_{\mathrm{s}}$ & $\circ$ & 2 & 30 \\
\hline Material of edges & & & $\mathrm{HM}$ & VHM \\
\hline \multicolumn{5}{|c|}{ Milling Processes Settings } \\
\hline \multirow{2}{*}{ Name of Parameter } & \multirow{2}{*}{ Symbol } & \multirow{2}{*}{ Unit } & \multicolumn{2}{|c|}{ Value } \\
\hline & & & AX 320 & SCM Tech Z5 \\
\hline Cutting speed & $v_{\mathrm{c}}$ & $\mathrm{m} \cdot \mathrm{s}^{-1}$ & 3.69 & 13.19 \\
\hline Spindle speed & $n$ & $\min ^{-1}$ & 4405 & 18000 \\
\hline Feed speed & $v_{\mathrm{f}}$ & $\mathrm{mm} \cdot \mathrm{min}^{-1}$ & 2848 & 6000 \\
\hline Feed per tooth & $f_{\mathrm{z}}$ & $\mathrm{mm}$ & 0.323 & 0.111 \\
\hline Average uncut chip thickness & $h_{\mathrm{av}}$ & $\mathrm{mm}$ & 0.14 & 0.066 \\
\hline Cut depth & $a_{\mathrm{p}}$ & $\mathrm{mm}$ & 25 & 22 \\
\hline Cut width & $a_{\mathrm{e}}$ & $\mathrm{mm}$ & 3 & 5 \\
\hline
\end{tabular}




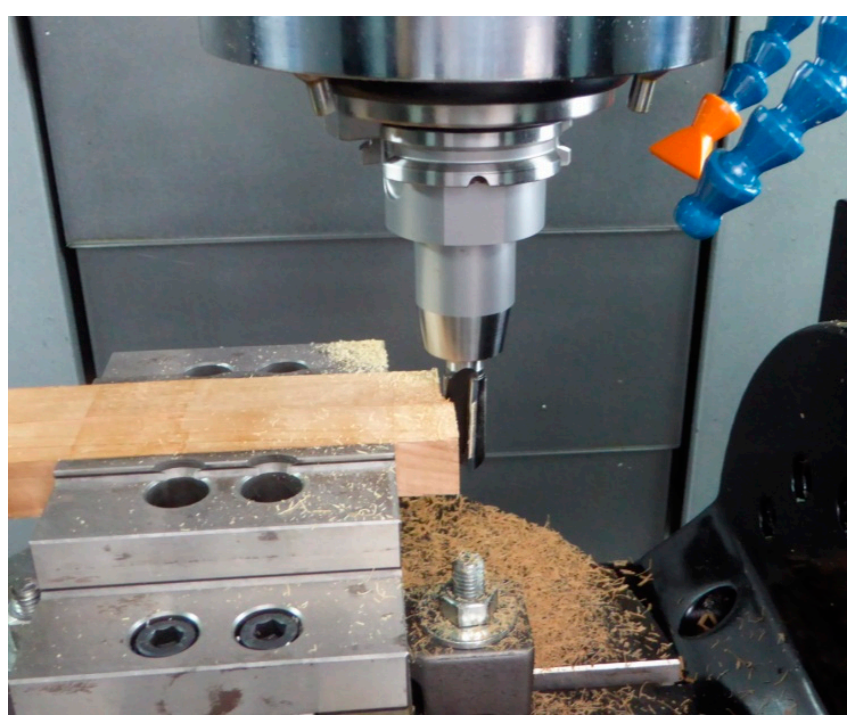

Figure 4. Machine tool AX320 Pinnacle with equipment for machining tests.

\subsubsection{Milling Centre SCM Tech Z5}

The birch blanks as well as after the heat treatment by the individual modes were milled on a 5 axis CNC machining centre SCM Tech Z5 manufactured by SCM-group, Rimini, Italy. A positive spiral milling cutter manufactured by IGM under the designation IGM 193 was used in the experiment (Figure 5). The working part of spiral cutter IGM 193 was manufactured with high-quality carbide VHM (Integral HM). The base technical data of this cutter are shown in Table 3.

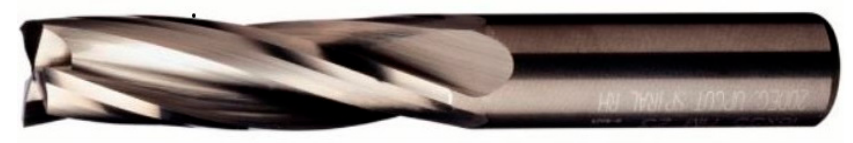

Figure 5. Mill cutter used for wood milling process at the SCM Tech Z5 milling centre.

\subsection{Granulometric Analysis of Chips}

For granulometric analyses of sawdust and shavings from the sawing and milling process of thermally untreated and treated birch wood, sawdust and chips samples were taken by isokinetic procedure from the exhaust pipe of the individual machine tools: PRW-15M frame saw, AX 320 Pinnacle and SCM Tech Z5 CNC machining centres, according to ISO 9096 [36].

A granulometric composition of the chips was evaluated by sifting. For this purpose, it was used a special set of sieves arranged one above the other (mesh size: 2, 1, 0.5, 0.25, 0.125, 0.063, $0.032 \mathrm{~mm}$, and the bottom), the sieves are placed on a vibration stand of the sifting machine Retsch AS 200c (Retsh $\mathrm{GmbH}$, Haan, Germany). The parameters of sifting were as follows: frequency of sifting interruption of $20 \mathrm{~s}$, amplitude of sieves deflection: $2 \mathrm{~mm} \cdot \mathrm{g}^{-1}$, sifting time: $\tau=15 \mathrm{~min}$, weighed sample: $50 \mathrm{~g}$. The granulometric composition was obtained by weighing of the portions remaining on the sieves after sifting on an electronic laboratory scale Radwag 510/C/2 (Radwag Balances and Scales, Radom, Poland), weighing to an accuracy of $0.001 \mathrm{~g}$. The sifting was realized with 3 samples for each combination of parameters.

With the purpose of specifying information about the size of the smallest particles of fine fraction of dry chips a microscopic analysis of granules of fraction of dry chips with the size lower than $500 \mu \mathrm{m}$ was realized. The proposed analysis of chips was carried out by an optical method-analysis of the picture obtained from the microscope Nikon Optiphot-2 with the objective Nikon $4 \times$. Granules of chips were scanned by three low-cost television CCD cameras HITACHI HV-C20 
(RGB $752 \times 582$ pixel), with horizontal resolution 700 TV lines and evaluated by a software LUCIA-G 4.0 (Laboratory Universal Computer Image Analysis), installed on a PC with the processor Pentium 90 (RAM $32 \mathrm{MB}$ ) with the graphic card VGA Matrox Magic under the operation system Windows NT 4.0 Workstation. The program of analysis of picture LUCIA-G enables to identify the individual particles of disintegrated wood material, quantitative determination of individual particles situated in the analyzed picture, and basic information such as width and length of particles, and circularity expressing the measure of deviation of projection of a given chip shape from the projection of the shape of a circle $\psi$ according to equation:

$$
\psi=\frac{4 \pi \cdot S}{P_{p}^{2}}
$$

where: $S$ - surface of particle $\left[\mathrm{m}^{2}\right], P_{\mathrm{p}}$-perimeter of particle $[\mathrm{m}]$.

\section{Results and Discussion}

The results of the sieve analysis of sawdust sucked off from the frame saw PRW-15M and the chips sucked off from the machining centre SCM Tech Z5, and AX320 Pinnacle from birch shavings with and without heat treatment, are shown in Tables 4-6.

Table 4. Sawdust from the saw frame PRW-15M, average values with standard deviations.

\begin{tabular}{|c|c|c|c|c|}
\hline \multirow{2}{*}{$\begin{array}{l}\text { Measure of Sieve } \\
\text { Mesh, }[\mathrm{mm}]\end{array}$} & \multirow{2}{*}{$\begin{array}{l}\text { Mark of } \\
\text { Fraction }\end{array}$} & \multicolumn{3}{|c|}{ Fractions Representation of Birch Wood [\%] } \\
\hline & & Untreated & Modified by Mode I & Modified by Mode II \\
\hline 2.000 & \multirow{2}{*}{ coarse } & $3.77 \pm 0.19$ & $3.11 \pm 0.16$ & $3.98 \pm 0.20$ \\
\hline 1.000 & & $2.82 \pm 0.14$ & $4.21 \pm 0.21$ & $1.80 \pm 0.09$ \\
\hline 0.500 & \multirow{3}{*}{$\begin{array}{l}\text { medium } \\
\text { coarse }\end{array}$} & $16.20 \pm 0.81$ & $14.84 \pm 0.74$ & $9.18 \pm 0.46$ \\
\hline 0.250 & & $52.30 \pm 2.62$ & $46.27 \pm 2.31$ & $47.13 \pm 2.36$ \\
\hline 0.125 & & $22.49 \pm 1.12$ & $28.30 \pm 1.42$ & $33.13 \pm 1.66$ \\
\hline 0.063 & \multirow{3}{*}{ fine } & $1.82 \pm 0.09$ & $3.20 \pm 0.16$ & $4.54 \pm 0.23$ \\
\hline 0.032 & & $0.61 \pm 0.03$ & $0.09 \pm 0.00$ & $0.25 \pm 0.01$ \\
\hline$<0.032$ & & $0.00 \pm 0.00$ & $0.00 \pm 0.00$ & $0.00 \pm 0.00$ \\
\hline
\end{tabular}

Table 5. Chips from AX320 Pinnacle, average values with standard deviations.

\begin{tabular}{ccccc}
\hline \multirow{2}{*}{$\begin{array}{c}\text { Measure of Sieve } \\
\text { Mesh, [mm] }\end{array}$} & \multirow{2}{*}{$\begin{array}{c}\text { Mark of } \\
\text { Fraction }\end{array}$} & \multicolumn{3}{c}{ Fractions Representation of Birch Wood [\%] } \\
\cline { 3 - 5 } & & Untreated & Modified by Mode I & Modified by Mode II \\
\hline 2.000 & coarse & $2.86 \pm 0.14$ & $2.52 \pm 0.13$ & $3.66 \pm 0.18$ \\
1.000 & & $4.74 \pm 0.24$ & $11.72 \pm 0.59$ & $4.44 \pm 0.22$ \\
\hline 0.500 & \multirow{2}{*}{ medium } & $30.95 \pm 1.50$ & $35.02 \pm 1.75$ & $30.15 \pm 1.51$ \\
0.250 & coarse & $40.92 \pm 2.05$ & $28.25 \pm 1.41$ & $33.59 \pm 1.68$ \\
0.125 & & $18.38 \pm 0.92$ & $18.14 \pm 0.91$ & $22.60 \pm 1.13$ \\
\hline 0.063 & \multirow{2}{*}{ fine } & $1.89 \pm 0.09$ & $4.22 \pm 0.21$ & $5.23 \pm 0.26$ \\
0.032 & & $0.27 \pm 0.01$ & $0.13 \pm 0.01$ & $0.33 \pm 0.02$ \\
$<0.032$ & & $0.00 \pm 0.00$ & $0.00 \pm 0.00$ & $0.00 \pm 0.00$ \\
\hline
\end{tabular}


Table 6. Chips from the CNC machining centre SCM Tech Z5, average values with standard deviations.

\begin{tabular}{ccccc}
\hline \multirow{2}{*}{$\begin{array}{c}\text { Measure of Sieve } \\
\text { Mesh, [mm] }\end{array}$} & \multirow{2}{*}{$\begin{array}{c}\text { Mark of } \\
\text { Fraction }\end{array}$} & \multicolumn{3}{c}{ Fractions Representation of Birch Wood [\%] } \\
\cline { 3 - 5 } & & Untreated & Modified by Mode I & Modified by Mode II \\
\hline 2.000 & coarse & $69.43 \pm 3.47$ & $66.25 \pm 3.31$ & $63.72 \pm 3.19$ \\
1.000 & & $6.28 \pm 0.31$ & $9.12 \pm 0.46$ & $8.67 \pm 0.33$ \\
\hline 0.500 & \multirow{2}{*}{ medium } & $10.14 \pm 0.51$ & $11.47 \pm 0.57$ & $10.23 \pm 0.51$ \\
0.250 & coarse & $9.13 \pm 0.46$ & $9.50 \pm 0.48$ & $8.71 \pm 0.44$ \\
0.125 & & $3.16 \pm 0.16$ & $2.02 \pm 0.29$ & $5.75 \pm 0.29$ \\
\hline 0.063 & \multirow{2}{*}{ fine } & $0.19 \pm 0.01$ & $0.12 \pm 0.01$ & $2.63 \pm 0.13$ \\
0.032 & & $0.00 \pm 0.00$ & $0.00 \pm 0.00$ & $0.29 \pm 0.01$ \\
$<0.032$ & & &
\end{tabular}

By comparing the proportions of the individual sawdust fractions of the PRW-15M frame saw (Table 4), it can be stated that there are no differences in the proportions of the sawdust fractions of natural birch wood and thermally treated birch wood. The distribution of chip fractions according to the distribution is symmetric, with the largest fraction in the grain size range of $0.250-0.500 \mu \mathrm{m}$.

Analyses of the shavings of individual sawdust fractions indicate that coarse and medium coarse fractions over $0.5 \mathrm{~mm}$ in size from the sawing process of both untreated and treated birch wood on the PRW-15M frame saw belong to the category of polydisperse fibrous materials, rod-shaped with significant elongation in one dimension. The agreement between the granulometric composition of the steam-saturated wood vapor at a temperature of $t=125-135^{\circ} \mathrm{C}$ and the granulometric composition of the native birch wood chips predicts that the thermal treatment of the birch wood does not affect the chip formation process. This finding is similar to the results of temperature analysis in the process of drying beech timber by low and high temperature regimes on sawdust grain size presented by Orlowski et al. [37].

Microscopic analysis of the chip shape of the fractions below $500 \mu \mathrm{m}$ indicates that the chip size of these fractions by their shape belongs to the group of isometric chips. Chips having approximately the same dimension in all three directions. Circularity is in the range $\Psi=0.7-1.0$.

The proportion of fractions of chip extracted from the machining centre AX320 Pinnacle (Table 5), is similar to sawdust from the PRW-15M frame saw. Chips from machining centre AX320 Pinnacle did not show any significant effect of birch wood thermal treatment on the particle size except for the increased proportion of fine fraction of thermally treated birch wood, which increased from $2.1 \%$ to $4.4 \%$ for thermally treated birch wood mode I, and to $5.5 \%$ for the thermally treated wood mode II.

From the chip shape aspect, only chips of a coarse fraction above $1 \mathrm{~mm}$ are fibrous chips. Medium and fine fraction chips are isometric chips with a circularity value in the interval: $\Psi=0.7-1.0$.

The chips formed at the SCM Tech Z5 machining centre (Table 6) differ according to the proportion of the individual fractions compared to the sawdust formed by sawing the birch wood on the PRW $15 \mathrm{M}$ sash gang saw. The coarse fraction chips above $2 \mathrm{~mm}$ make up to $2 / 3$ of the total chips produced. Similar representation of the fractions of beech, maple, and oak wood chips at the SCM Tech Z5 machining centre at a removal of $a_{\mathrm{e}}=3 \mathrm{~mm}$ and a feed speed $v_{f}=3 \mathrm{~m} \cdot \mathrm{min}^{-1}$, and at feed speed $v_{f}=5 \mathrm{~m} \cdot \mathrm{min}^{-1}$ reported by: Kminiak and Banski [38]. With the feed speed decreasing at this machining centre when milling wood as the authors stated [39], the share of the coarse fraction is increasing at the expense of the medium coarse fraction.

The chip shape of the coarse fraction corresponds to the shape and size of the layer to be cut. Medium and fine fractions of birch wood chips with or without thermal treatment are isometric chips.

A comparison of the dust fraction of the extracted sawdust from the PRW-15M frame sawing machine and the chips extracted from the CNC machining centres suggests that the smallest chips in the extracted bulk wood mass are chips of size $a=32 \mu \mathrm{m}$ (Figure 6). Fractions below $30 \mu \mathrm{m}$ (thoracic dust or respirable dust) were not detected by measurements. 


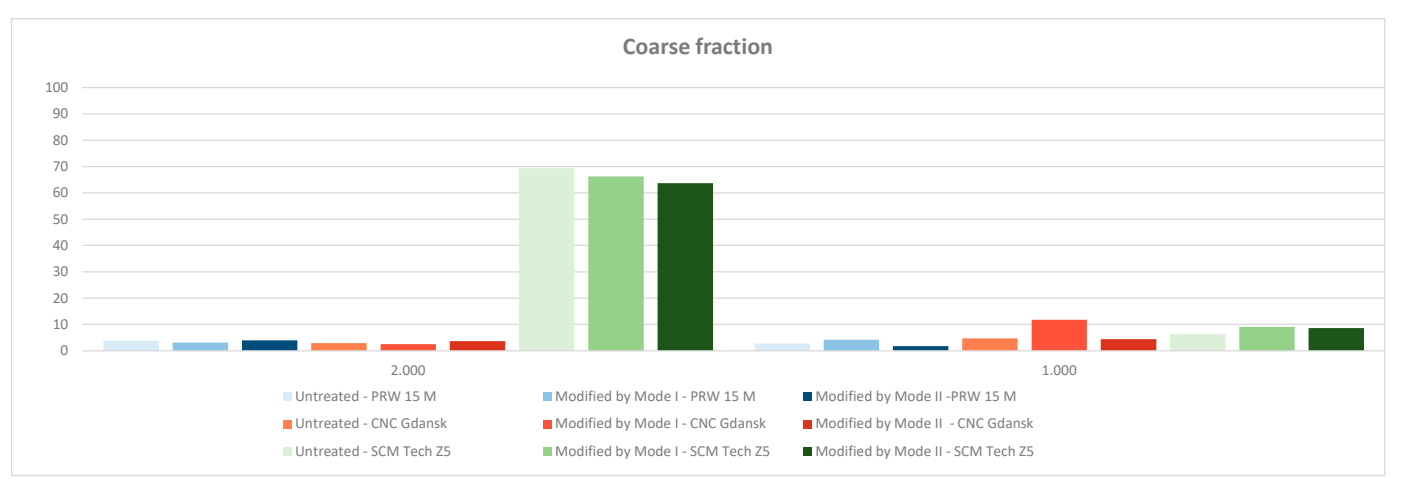

(a)

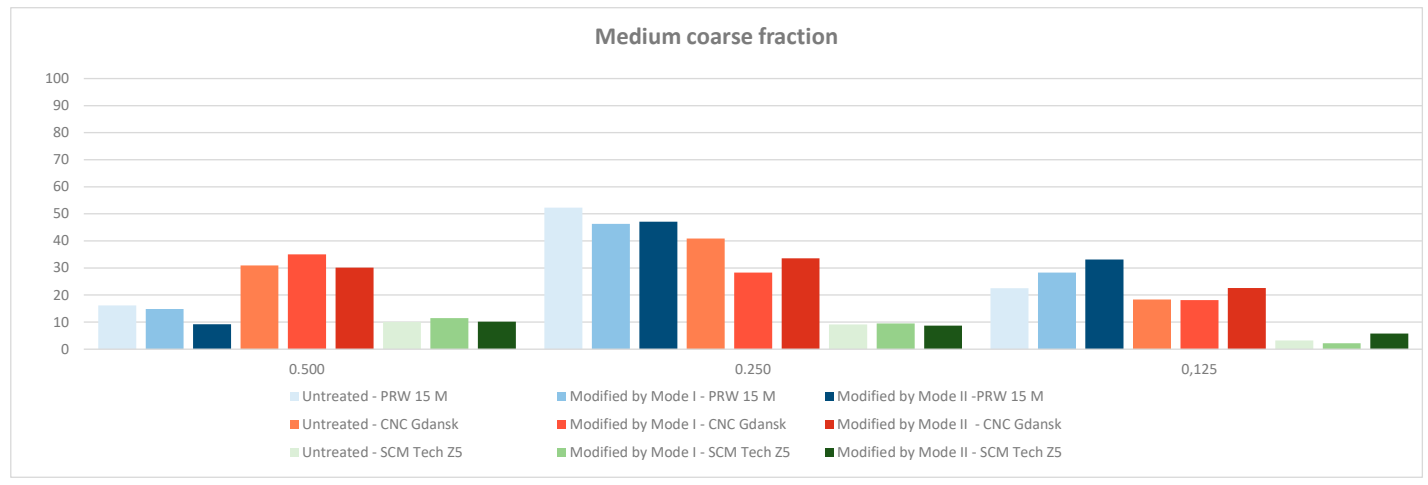

(b)

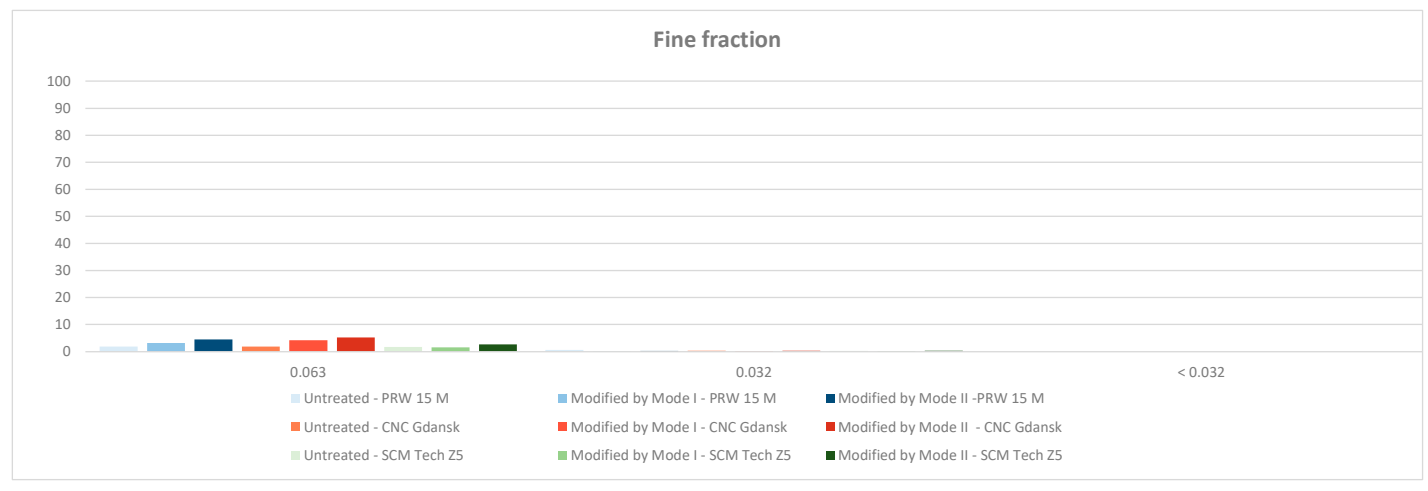

(c)

Figure 6. Comparison of sawdust and chips fractions from $\mathrm{CNC}$ machining centres (a) coarse fraction (b) medium coarse fraction (c) fine fraction.

Criterion for establishing a separation technique requirement for the separation of extracted bulk solids, including dust chips from conveyed air in exhaust systems is the limit of separation of separation technology. By comparing the smallest chips in the conveyed bulk material from individual machines $a=32 \mu \mathrm{m}$ with the separability limit of the separators in Figure 7, the possibility of meeting environmental criteria is demonstrated. Separation limits of selected filters and separators are shown in Table 7. 


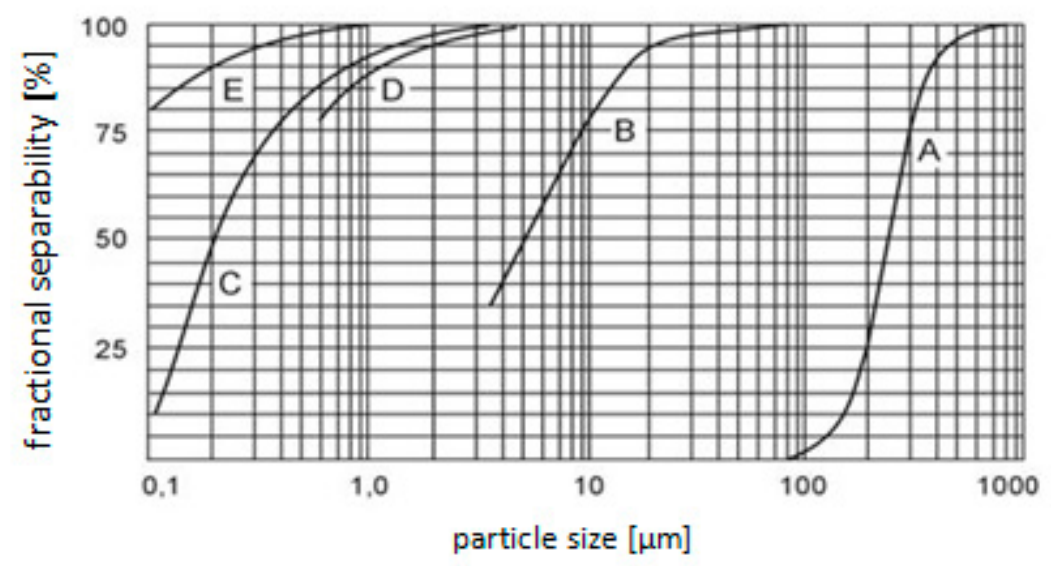

Figure 7. Fractional separation diagram of disintegrated wood mass of individual types of separation technique: A-settling chambers, B-dry mechanical separators, C-fabric filters, D-wet separators, E-electrofiltrators.

Table 7. Separation limits for separation technique.

\begin{tabular}{cc}
\hline Type of Separation Device & Separation Limits \\
\hline dry mechanical separators & $a=80[\mu \mathrm{m}]$ \\
fabric filters with fabric class G4 & $a=10[\mu \mathrm{m}]$ \\
electro separators & $a=1[\mu \mathrm{m}]$ \\
\hline
\end{tabular}

Based on data in Table 4 and Figure 6, it follows that for separating chips with dimensions above and $\geq 32 \mu \mathrm{m}$, suitable separation techniques are: wet scrubbers, fabric filters, and electro-scrubbers.

For the purpose of separating loose wood from transport air in wood processing plants, the best available technology are filters with G4 fabric having a separation limit value of $a_{\mathrm{SL}}=10 \mu \mathrm{m}$, thus meeting the requirements of EN 779/2012 [40].

Fabric filters are fully sufficient to catch the chips extracted from the sawing and milling process native birch wood, and thermally modified wood with saturated water vapor [38-41].

Analyses of the grain size of chips formed in the processes of sawing dried birch wood on PRW-15M frame saws and milling on CNC machining centers showed that heat treatment of birch wood with saturated steam did not affect the grain size of the chips. Based on this fact, it can be concluded that, just as chips from raw birch wood are used for the production of composite materials, chips from heat treatment birch wood are also a suitable raw material for the production of composite materials. The use of a given chip to produce agglomerated materials prolongs the life cycle of wood and thus contributes to increasing the degree of sustainability.

\section{Conclusions}

The following conclusions are drawn from the performed granulometric analyses of the extracted sawdust from the frame saw PRW 15M and the chips of the extracted CNC machining centre in order to evaluate the inlet of the thermal modification of the birch wood by the saturated water steam to modify the wood colour:

- The influence of thermal treatment of birch wood did not affect the grain size of sawdust from the PRW $15 \mathrm{M}$ frame saw or the grain chips from CNC centre.

- In the process of sawing birch wood on the frame saw PRW-15M and milling on CNC machining centres, chips are formed with a dominant representation of medium and coarse fractions larger than $125 \mu \mathrm{m}$.

- $\quad$ The dust fraction in the grain size range of $125-32 \mu \mathrm{m}$ does not exceed $5 \%$. 
- Fractions of thoracic or respirable dust with particle sizes below $30 \mu \mathrm{m}$ have not been detected.

- These values are fully in line with the particle sizes used for the production of wood composites and it is not possible to consider reducing the quality of the input raw material for the production of wood composites.

- Environmental criteria for the separation of chips from transport air are met by fabric filters with a fabric classified in G4 filtration class.

Author Contributions: Conceptualization, L.D., K.A.O., D.C. and R.K.; methodology, L.D. and D.C.; software, D.C. and R.K.; validation, L.D. and K.A.O.; formal analysis, L.D. and R.K.; investigation, L.D., K.A.O., D.C. and R.K.; resources, L.D., K.A.O., D.C., R.K. and A.B.; data curation, L.D. and K.A.O.; writing-original draft preparation, L.D., K.A.O., D.C., R.K. and A.B.; writing-review and editing, L.D., K.A.O., D.C. and R.K.; visualization, L.D., K.A.O., D.C., R.K. and A.B.; supervision, L.D. and K.A.O.; project administration, L.D., K.A.O. and D.C.; funding acquisition, R.K. and D.C. Please turn to the CRediT taxonomy for the term explanation. Authorship must be limited to those who have contributed substantially to the work reported. All authors have read and agreed to the published version of the manuscript.

Funding: This research was funded by Slovak Research and Development Agency, grant number APVV-17-0456 and by Polish Ministry of Science and Higher Education, decision number 21/E-359/SPUB/SP/2019.

Acknowledgments: This experimental research was prepared within the grant project: APVV-17-0456 "Termická modifikácia dreva sýtou vodnou parou za účelom cielenej a stabilnej zmeny farby drevnej hmoty" as the result of work of authors and the considerable assistance of the APVV Agency. The authors gratefully acknowledge the Polish Ministry of Science and Higher Education for funding the maintenance of scientific and research equipment-PRW-15M frame saw (decision no. 21/E-359/SPUB/SP/2019).

Conflicts of Interest: The authors declare no conflict of interest.

\section{References}

1. Fengel, D.; Wegener, G. Wood: Chemistry, Ultrastructure, Reactions; Walter de Gruyter: Berlin, Germany, 1989; p. 613.

2. Hon, N.S.D.; Shiraishi, N. Wood and Cellulosic Chemistry; CRC Press: New York, NY, USA, 2001; p. 928.

3. Kačíková, D.; Kačík, F.; Čabalová, I.; Ďurkovič, J. Effects of thermal treatment on chemical, mechanical and colour traits in Norway spruce wood. Bioresour. Technol. 2013, 144, 669-674. [CrossRef] [PubMed]

4. Timar, M.C.; Varodi, A.M.; Hacibektasoglu, M.; Campean, M. Color and FT-IR analysis of chemical changes in beech wood (Fagus sylvatica L.) after light steaming and heat treatment in two different environments. BioResources 2016, 11, 8325-8343. [CrossRef]

5. Sikora, A.; Kačík, F.; Gaff, M.; Vondrová, V.; Bubeníková, T.; Kubovský, I. Impact of thermal modification on color and chemical changes of spruce and oak wood. J. Wood Sci. 2018, 64, 406-416. [CrossRef]

6. Geffert, A.; Výbohová, E.; Geffertová, J. Characterization of the changes of colour and some wood components on the surface of steamed beech wood. Acta Fac. Xylologiae Zvolen 2017, 59, 49-57. [CrossRef]

7. Dzurenda, L.; Geffert, A.; Geffertová, J.; Dudiak, M. Evaluation of the process thermal treatment of maple wood saturated water steam in terms of change of $\mathrm{pH}$ and color of wood. BioResources 2020, 15, 2550-2559. [CrossRef]

8. Tolvaj, L.; Nemeth, R.; Varga, D.; Molnar, S. Colour homogenisation of beech wood by steam treatment. Drewno 2009, 52, 5-17.

9. Deniz, A.; Gokhan, G.; Seray, O. The influence of thermal treatment on color response of wood materials. Color Res. Appl. 2012, 37, 148-153. [CrossRef]

10. Hadjiski, M.; Deliiski, N. Advanced control of the wood thermal treatment processing. Cybernetics and information technologies. Bulg. Acad. Sci. 2016, 16, 176-197.

11. Dzurenda, L. The shades of color of quercus robur L. Wood obtained through the processes of thermal treatment with saturated water vapor. BioResources 2018, 13, 1525-1533. [CrossRef]

12. Banski, A.; Dudiak, M. Dependence of color on the time and temperature of saturated water steam in the process of thermal modification of beech wood. AIP Conf. Proc. 2019, 2118, 030003. [CrossRef]

13. Sandak, J.; Goli, G.; Cetera, P.; Sandak, A.; Cavalli, A.; Todaro, L. Machinability of minor wooden species before and after modification with thermo-vacuum technology. Materials 2017, 10, 121. [CrossRef] [PubMed] 
14. Kos, A.; Beljo-Lučić, R.; Šega, K.; Rapp, A.O. Influence of woodworking machine cutting parameters on the surrounding air dustiness. Holz Als Roh Und Werkst. 2004, 62, 169-176. [CrossRef]

15. Očkajová, A.; Beljo Lučić, R.; Čavlović, A.; Teraňová, J. Reduction of dustiness in sawing wood by universal circular saw. Drv. Ind. 2006, 57, 119-126.

16. Kopecký, Z.; Rousek, M. Dustiness in high-speed milling. Wood Res. 2007, 52, 65-76.

17. Orlowski, K.A.; Sandak, J.; Negri, M.; Dzurenda, L. Sawing frozen wood with narrow kerf saws: Energy and quality effects. Forest Prod. J. 2009, 59, 79-83.

18. Dzurenda, L.; Orlowski, K.A.; Grzeskiewicz, M. Effect of thermal modification of oak wood on sawdust granularity. Drv. Ind. 2010, 61, 89-94.

19. Hlásková, L.; Rogozinski, T.; Dolny, S.; Kopeckỳ, Z.; Jedinák, M. Content of respirable and inhalable fractions in dust created while sawing beech wood and its modifications. Drewno 2015, 58, 135-146.

20. Mračková, E.; Krišt'ák, L'.; Kučerka, M.; Gaff, M.; Gajtanska, M. Creation of wood dust during wood processing: Size analysis, dust separation, and occupational health. BioResources 2015, 11, 209-222. [CrossRef]

21. Hlásková, L.; Rogozinski, T.; Kopecký, Z. Influence of feed speed on the content of fine dust during cutting of two-side-laminated particleboards. Drv. Ind. 2016, 67, 9-15. [CrossRef]

22. Pałubicki, B.; Rogoziński, T. Efficiency of chips removal during CNC machining of particleboard. Wood Res. 2016, 61, 811-818.

23. Marková, I.; Hroncová, E.; Tomaškin, J.; Tureková, I. Thermal analysis of granulometry selected wood dust particles. Bioresources 2018, 13, 8041-8060. [CrossRef]

24. Piernik, M.; Rogozinski, T.; Krauss, A.; Pinkowski, G. The influence of the thermal modification of pine (Pinus sylvestris L.) wood on the creation of fine dust particles in plane milling. J. Occup. Health 2019, 61, 481-488. [CrossRef] [PubMed]

25. Tureková, I.; Marková, I. Ignition of deposited wood dust layer by selected sources. Appl. Sci. 2020, 10, 5779. [CrossRef]

26. Mirski, R.; Derkowski, A.; Dziurka, D.; Wieruszewski, M.; Dukarska, D. Effects of chip type on the properties of chip-sawdust boards glued with polymeric diphenyl methane diisocyanate. Materials 2020, 13, 1329. [CrossRef]

27. Očkajová, A.; Kučerka, M.; Kminiak, R.; Krišt’ák, L'; Igaz, R.; Réh, R. Occupational exposure to dust produced when milling thermally modified wood. Int. J. Environ. Res. Public Health 2020, 17, 1478. [CrossRef]

28. Pałubicki, B.; Hlásková, L.; Rogoziński, T. Influence of exhaust system setup on working zone pollution by dust during sawing of particleboards. Int. J. Environ. Res. Public Health 2020, 17, 3626. [CrossRef]

29. Rogozinski, T. Pilot-scale study on the influence of wood dust type on pressure drop during filtration a pulse-jet baghouse. Process Saf. Environ. Prot. 2018, 119, 58-64. [CrossRef]

30. Očkajová, A.; Kučerka, M.; Kminiak, R.; Rogoziński, T. Granulometric composition of chips and dust produced from the process of working thermally modified wood. Acta Fac. Xylologiae Zvolen 2020, 62, 103-111. [CrossRef]

31. Dzurenda, L.; Orlowski, K.A. The effect of thermal modification of ash wood on granularity and homogeneity of sawdust in the sawing process on a sash gang saw PRW 15-M in view of its technological usefulness. Drewno 2011, 54, 27-37.

32. Youngquist, J.A. Wood-based composites and panel products. In Wood Handbook-Wood as an Engineering Material; United States Department of Agriculture, Ed.; USDA: Madison, WI, USA, 1999; pp. 10-31.

33. Maloney, T.M. Modern Particleboard \& Dry-Process Fiberboard Manufacturing, 2nd ed.; Miller Freemann Inc.: San Francisco, CA, USA, 1993; 689p.

34. Istek, A.; Aydin, U.; Özlüsoylu, I. The effect of chip size on the particleboard properties. In Proceedings of the International Congress on Engineering and Life Science (ICELIS), Kastamouno, Turkey, 26-29 April 2018; pp. 439-444.

35. Wasielewski, R.; Orłowski, K.A. Hybrid dynamically balanced saw frame drive. Holz als Roh-Und Werkst. 2002, 60, 202-206. [CrossRef]

36. ISO 9096. Stationary Source Emissions-Manual Determination of Mass Concentration of Particulate Matter; The International Organization for Standardization: Geneva, Switzerland, 2017.

37. Orłowski, K.A.; Chuchała, D.; Muziński, T.; Barański, J.; Banski, A.; Rogoziński, T. The effect of wood drying method upon the granularity of sawdust obtained during the sawing process on the frame sawing machine. Acta Fac. Xylologiae Zvolen 2019, 61, 83-92. [CrossRef] 
38. Kminiak, R.; Banski, A. Separation of exhausted chips from a CNC machining center in filter FR-SP 50/4 with finet PES 4 fabric. AIP Conf. Proc. 2018, 2000, 30011. [CrossRef]

39. Kminiak, R.; Dzurenda, L. Impact of sycamore maple thermal treatment on a granulometric composition of chips obtained due to processing on a CNC machining centre. Sustainability 2019, 11, 718. [CrossRef]

40. EN 779. Particulate Air Filters for General Ventilation-Determination of the Filtration Performance; The International Organization for Standardization: Geneva, Switzerland, 2012.

41. Dolny, S.; Rogozinski, T. Air flow resistance nonwoven filter fabric covered with Microfiber layer used in wood dust separation. Drewno 2014, 57, 125-134.

Publisher's Note: MDPI stays neutral with regard to jurisdictional claims in published maps and institutional affiliations.

(C) 2020 by the authors. Licensee MDPI, Basel, Switzerland. This article is an open access article distributed under the terms and conditions of the Creative Commons Attribution (CC BY) license (http://creativecommons.org/licenses/by/4.0/). 